\title{
MOLECULAR GENETIC VARIATIONS AMONG ADJACENT POPULATIONS OF FRESHWATER SNAILS THAT ARE TARGET AND NON-TARGET TO SCHISTOSOMA INFECTION
}

\author{
Abdel - Hamid Z. Abdel - Hamid ${ }^{1}$, Samia M. Abd El - Wahab \\ ${ }^{2}$, Mona M. El - Tonsy ${ }^{2}$ and Rehab M. Abdel - Megeed ${ }^{1}$ \\ Medicinal Chemistry Department, National Research Center ${ }^{1}$ and \\ Zoology Department, Faculty of Science ${ }^{2}, \mathrm{Al}$ - Azhar University for \\ Girls , Cairo, Egypt.
}

Keywords: Schistosomiasis, Biomphalari, Schistosoma, genetic Control. polymorphism, biological control, molecular marker

\section{ABSTRACT}

chistosomiasis is one of the most important public health problems in Omany developing countries and it is the prime health problem in Egypt. Since the infection of Biomphalaria alexandrina and Biomphalaria glabrata snails by the parasitic trematode Schistosoma mansoni depends on the complex interactions by both parasite and snail genes, genetic control is one of the successful means for control of schistosomiasis . A number of laboratory derived stocks of B. alexandrina and $B$. glabrata have been used to sort out this complex genetic relationship. In the present study genetic variations between adjacent snail populations., target ( $B$. alexandrina and B. glabrata) and non-target (Lymnaea truncatula and Physa acuta) to Schistosoma infection was investigated using DNA amplification by random amplified polymorphic DNA - polymerase chain reaction ( RAPD-PCR ) at different developmental stages. The amplitication products were analyzed on $6 \%$ polyacrylamide gel and staned with silver. Eighteen primers were selected, since they have previously 'been 'useful to detect polymorphism" among $B$. alexandrina and $/$ or $B$. glabrata .The results showed polymorphism with 3 primers; OPA-01, OPA-02 and OPA-18. Stable reproducible RAPD markers with utilized primers OPA-01, OPA-02 of $B$. alexandrina and $B$. glabrata showed highly genetic variation among different snail types and ages. Eurthermere Hybrid snails obtained genetic polymorphism at one strain ( susceptible or resistant ) among different developmental stages by primers OPA-01, OPA-02 and OPA18. The results resolved the problem of susceptibility / age association of 
intermediate: snail host. The present study showed that by comparing targets ( both susceptible and resistant strains ) with non-target species to Schistosoma infectionlwhere is a genetic polymorphism. specific for resistant snails and contirmed in non-target species obtained by primer OPA- $01 \%$ Since, the resistant character is heritable like susceptrbility , it would be beneficial to select actively resistant snails and mass cultufe them to increase the proportion of alleles for insusceptibility as a possible mean for biological control of schistosomiasis in natural population.

\section{INTRODUCTION}

Schistosomiasis remains one of the most prevalent parasitic infections and has significant economic public health consequences in many developing countries (WHO, 2004). Egypt is considered one of the most endemic area in the world in some localities in the Nile Valley as reported by Lotfy et al.(2005). A large number of schistosomes is known, however, only five appeared to be primarly responsible for human infections. These include $S$. marsoni, $S$. japonicum, $S$. intercalatum, $S$. mekongi and $S$. haematobium. Infection with the former 4 species is associated with chronic hepatic and intestinal fibrosis, while infection with $S$. haematobium may lead to ureteric and bladder fibrosis and calcification of the urinary tract ( Ross et al., 2002 ). Schistosome parasites are transmitted by snail intermediate hosts in water bodies like lakes, ponds, streams, rivers and irrigation canals. Two species of Biomphalaria are reported from Egypt, the indigenous Biomphalaria alexandrina and Biomphalaria glabrata; the latter is belived to be introduced during the last decade. Both are known to be excellent hosts to Schistosoma mansoni, the human-infecting blood fluke common in Egypt ( Lotfy et al., 2005).

The control of intermediate host snails is important in integrated schistosomiasis control. Methods of control include chemical ( use of molluscicides ) and biological measures. Molluscicides are expensive, toxic to life and environment and have temporary effect (Ukoli, 1992 ). Biological control is cheap and based on the use of predators or parasites, alteration of habitate and introduction of competitors to reduce target species ( Jobin et al., 1984 ). Currently, the most efficient method of schistosomiasis control involves chemotherapeutic treatment of patients with praziquantel ( Fenwick et al., 2003 ). However, reports suggest that schistosome populations in some endemic areas may develop resistance to praziquantel ( Ismail et al., 1998 \& 1999 ). Therefore, there is a need to 
apply efficient method for transmission effective control in conjunction with chemotherapy and vaccine development in order to bring this hazardous disease under an adequate control .

The concept of snail control has gained a considerable interest being easier, cheaper, safer and more promising, since, there is a high degree of specificity of schistosomes, as well as of other trematodes, to their intermediate snail hosts. A schistosome miracidium might penetrate several species of snails, but its fate in the tissues of the snail is determined by both biochemical adaptation to certain species and interactions between host and parasite genome. It might develop and produce cercariae in some species, whereas in others is walled off as a result of the internal defense system of the host ( Bayne and Yoshino, 1989 ).

In snail / schistosome combination, some snails are actually resistant to parasite infection. Understanding the genetics involved in the complex host / parasite relationship may lead to select actively resistant snails and mass culture them to increase the proportion of alleles for insusceptibility as a possible mean for biological control of schistosomiasis in natural population .

As reported by Rollinson et al. (1998), the identification of resistant snails in natural populations is based on the use of molecular markers, which help in studying host / parasite relationship in schistosomiasis . They reported that snails resistant to infection occur naturally and there is a genetic basis for this resistance.

Since the morphological differentiation among strains and species of Biomphalaria snails is greatly complicated by extensive intraspecific variation of morphological characteristics, the use of molecular genetic technique as an additional tool for the identification of these snails has been proposed. It is also used to distinguish among closely related individuals within the same snail species. The aim of the present work is to emphasize our interest in molecular genetic of the snails in order to study the infection rate in different developmental stages of the target snails ( $B$. alexandrina and B. glabrata) to Schistosoma parasite and comparing them with non - target ones ( L. truncatula and P. acuta). This concept will open the way for the elucidation of the genetic basis for schistosome resistance within the intermediate host snails and for selection and breeding of resistant genetic strains of Biomphalaria snails as a development of new strategies for the control of schistosomiasis . 


\section{Maintenance of snails :}

\section{MATERIAL AND METHODS}

Target and non-target snail species for Schistosoma infection ( Biomphalaria alexandrina', Biomphalaria glabrata, Lymnaea truncalula and Physa acuta) were obtained from the field (Giza governorate, Egypt)

Each species of these snails were maintained as stock cultures, in a well prepared snail room, under suitable environmental conditions, in glass aquaria ( $40 \times 30 \times 20 \mathrm{~cm}$ ), each containing 5 liter of snail conditioned water ( $\mathrm{SCW}$ ) $\left[\mathrm{pH}=7.0 \pm 0.2\right.$ at $\left.25^{\circ} \mathrm{C}\right]$, at a density of 10 snails / litre as described by Abdel - Hamid ( 1996 ). The snails were fed on fresh lettuce leaves supplemented with tetramin (fish food) [ ingredient statement : fish meat, shrimp meat, aquatic plants, oat flour yeast, various vitamins, chlorophyll ] . Adult snails readily deposited their eggs on a plastic sheets floating on the surface of water.

After careful selection on the basis of health, size and age, methods of separating schistosome resistant and susceptible snails of both $B$. alexandrina and B. glabrata were performed according to the method described by Zanotti - Magalhaes et al. (1997) .

Adult snails ( $6 \pm 1 \mathrm{~mm}$ in diameter ) were exposed individually to 10 freshly hatched miracidia of $S$. mansoni-Egyptian strain obtained from Schistosome Biological Supply Project ( SBSP ), ( Theodur Bilharz Research Institute, Egypt ) in vials containing $3 \mathrm{ml}$ water for $3-4$ hours . A dose of 10 miracidia is considered as a high dose, minimizing the risk of the residual variability of the strain of $S$. mansoni as reported by Langand and Morand ( 1998 ). Each tested snail was returned and reared singly in a beaker containing $500 \mathrm{ml} \mathrm{SCW}$.

Snails were examined after 10 days post-exposure and checked for infection with a binocular microscope. Snails with developing sporocysts were transferred to another flask and held for cercarial emergence for 10 weeks post-exposure to avoid any delayed development of parasites. Snails in which developing parasites are not evident were re - exposed individually to 10 miracidia / snail . As described by Larson et al. (1996), snails in which high infection rates were observed were considered susceptible and those that remain uninfected after two exposures were considered as resistant .

Sclfing / out crossing :

Both susceptible and resistant parent stocks of either $B$. alexandrina or $B$. glabrata snails were isolated and reared singly for self fertilization . 
These self fertilized snails were used for breeding and for current study as following : -

Different developmental stages juvenile ( $\mathrm{J}$ ), adult ( Ad ) and senescent ( $\mathrm{Se}$ ) from either susceptible or resistant strains were obtained in successive generations by rearing snails singly each in $500 \mathrm{ml}$ plastic container containing SCW . On the other hand, crosses among adult and senescent snails were performed.

To confirm hybridization phenomenon within both $B$. alexandrina and $B$. glabrata, the following experiment was conducted. Four groups of snails, each contains one $B$. alexandrina ( either susceptible or resistant ) and one $B$. glabrata ( susceptible or resistant) were left to live in pairs in clean plastic containers ( $500 \mathrm{ml}$ ). Snails progenies were examined using RAPD-PCR technique to differentiate genetically between B. alexandrina, B. glabrata and hybrid snails .

Molecular analysis :

The snails were subjected to different molecular techniques as follows:

- DNA extraction :

DNA was extracted from the tip of the head foot region of the individual snail of both target ( $B$. alexandrina and B. glabrata) and nontarget ( $P$. acuta and L. truncatula) in different ages ( juveniles, adults and senescent ), using lysis buffer containing $2 \%$ hexadecyl trimethyl ammonium bromide ( CTAB ) as described by Winnepenninckx et al . ( 1993 ) and modified by Abdel - Hamid et al . ( 1999 ) to overcome the problems associated with DNA degradation .

- Spectrophotometric determination of DNA :

DNA concentration was accurately measured spectrophotometrically (Rodgers and Bendich, 1988).

- Agarose gel electrophoresis of genomic DNA : agarose gels are used to separate large DNA fragments as described by Helling et al. ( 1974 ).

- Amplification of DNA using RAPD - PCR :

The genotype of both target and non-target snails to Schistosoma infection were determined using 18 arbitrary 10 primers (OPA-01 to OPA-18) by RAPD-PCR - technology according to the method of Simpson et al . ( 1993 ).

- Polyacrylamide gel electrophoresis :

After DNA thermal cycle, PCR products were analyzed by gel electrophoresis as described by Vidigal et al . (1996) and silver staining to resolve amplified fragments (Sanguinetti et al. ( 1994 ). 


\section{Statistical analysis :}

Statistical analysis of the results was carried out using analysis of variance (ANOVA) according to Campbell (1989). -Polymorphic analysis of amplified DNA fragment:

To calculate percentage band differences between target (susceptible and resistant ) and non-target snail species, the bands observed in a given lane were compared with those in other lanes of the same gel as described by Vidigal et al. ( 1994 ).

The similarity level was calculated using Dice coefficient and genetic distance using the Nei and $\mathrm{Li}$ coefficient ( Nei and Li , 1979).

Nei's estimate of similarity, based on the probability that an amplified fragment from one isolate will also be found in another. To generate the similarity matrix, the following equation was used .

$2 \times$ number of shared fragments

$\mathrm{DBA}=$

Number of fragments $\mathrm{A}+$ number of fragment $\mathrm{B}$

\section{RESULTS}

DNA genome of both target ( $B$. alexandrina and $B$. glabrata) and non-target ( $P$. acuta and $L$. truncatula) snails to $S$. mansoni infection:

Data listed in Table ( 1 ) show that the mean snail foot weight for any given individual snail of target species ranging from 8.01 to $8.09 \mathrm{mg}$ for jureniles , 50.01 to $50.8 \mathrm{mg}$ for adults and 101.00 to $105.90 \mathrm{mg}$ for senescent stage. The degrees of purity of all specimens tested are greater than 1.7. Table ( 2 ) shows that the mean snail foot weight for any given individual non-target species ( $L$. truncatula and $P$. acuta) ranged from 7.99 to 8.09 for juveniles , 46.75 to 60.32 for adults and 90.23 to 119.23 $\mathrm{mg}$ for senescent snails respectively. The degrees of purity of all specimen tested ranged from 1.69 to 1.85 .

However, Tables $1 \& 2$ and Figure 1 show that the protocol of DNA extraction using $C T A B$ buffer has proved for isolation of high molecular weight DNA from target and non- target molluscan species, since the total DNA genome gave basically similar pattern as that of the marker and there was no degradation or contamination with RNA.

\section{Genomic DNA Amplification :}

Genetic variations between target and non-target species to $S$. mansoni were determined by RAPD-PCR technique using different primers . Of the available 18 primers tested, 15 showed no polymorphism among snail lines, and the identified polymorphisms were not 
reproducible among individual isolates of the same line. Three out of 18 tested primers gave amplification products (OPA-01, OPA-02, OPA-18), which were selected on the basis of the number and frequency of polymorphism produced among the different snail strains .

\begin{tabular}{|l|l|}
\hline Primer & $\begin{array}{l}\text { Sequence } \\
5^{\prime} \rightarrow 3^{\circ}\end{array}$ \\
\hline OPA-01 & CAGGCCCTTC \\
\hline OPA-02 & TGCCGAGCTG \\
\hline OPA-18 & AGGTGACCGT \\
\hline
\end{tabular}

Fig. 2 illustrates the amplified fragments in susceptible $B$. alexandrina at different developmental stages. The amplified fragments obtained by primer OPA-01 showed a highly genetic variability at $700 \mathrm{bp}$ in juvenile and adult stages only, $620 \mathrm{bp}$ in juvenile , 460 , 200 $\mathrm{bp}$ in senescent and $250 \mathrm{bp}$ in adult and senescent stages .

Fig. 3 shows the amplified fragments obtained by gel electrophoresis of resistant $B$. alexandrina at different ages, using OPA-01, since genetic markers at $700 \mathrm{bp}$ in juvenile, $200 \mathrm{bp}$ in senescent and $180 \mathrm{bp}$ in both adult and senescent stages were observed. Lanes 4, 5 and 6 resistant amplified DNA of juvenile, adult and senescent, respectively, using primer OPA-02 showed genetic markers at 720 bp, 600 bp, 580 bp, 430 $\mathrm{bp}, 400 \mathrm{bp}$ in both juvenile and adult stages. It was also noticed that the primer OPA-18 did not give any amplified DNA fragment which was injected in lanes 7, 8, 9 for juvenile, adult and senescent stages respectively.

Fig. 4 illustrates PCR products on polyacrylamide gel electrophoresis for susceptible $B$. glabrata at different ages ( juvenile, adult and senescent ). Gene regulation revealed in senescent stage at $300 \mathrm{bp}$ and in both adult and senescent stages at 340 bp obtained by primer OPA-01. Furthermore, the primer OPA-02 showed genetic markers in juvenile at $360 \mathrm{bp}$ and in senescent stage at 300 and $400 \mathrm{bp}$. Moreover, 500 and 520 bp in both juvenile and adult stages were detected.

Fig. 5 demonstrates PCR products obtained by polyacrylamide gel electrophoresis of resistant $B$. glabrata at different ages, showing genetic polymorphism at $340 \mathrm{bp}$ in juvenile and adult and $430 \mathrm{bp}$ in both adult and senescent stages .

Furthermore, lanes 4, 5 and 6 showed genetic polymorphism at 660 and $165 \mathrm{bp}$ in both juvenile and adult stages, while $640,340,280$ and $180 \mathrm{bp}$ were recorded in juvenile stage only by primer OPA-C2 . 
Fig. 6 represents PCR products on polyacrylamide gel electrophoresis using primers ( OPA-01, OPA-02 and OPA-18) for hybrid strain ( susceptible ) at different stages. It is noticed that the 3 used primers gave reproducible bands.

The results demonstrated a remarkable genetic markers at $700 \mathrm{bp}$ in senescent stage with primer OPA-01. Moreover the primer OPA-02 identified 1030, 340, and $180 \mathrm{bp}$ in both adult and senescent stages . Primer OPA-18 also illustrated genetic polymorphism at 1050, 1030 and $950 \mathrm{bp}$ in juvenile stage only.

It is clear from Fig. 7 that the electrophoresis scanning of amplified DNA of resistant hybrid strain showed reproducible bands with primers OPA-01, OPA-02 and OPA-18 at different stages of development except juvenile stage which did not have any amplified fragments produced by primers OPA-02 .

The result showed polymorphic bands at $350 \mathrm{bp}$ in adult and senescent and $320 \mathrm{bp}$ in senescent stage using primer OPA-01 . Primer OPA-18 showed genetic marker at 600,500 and $430 \mathrm{bp}$ in juvenile, 300 bp in both juvenile and adult and $320 \mathrm{bp}$ in senescent stage only .

Genetic variability of target and non-target genotype markers identified by OPA-01 primer :

Relative to the electrophoresis profiles of known weights of major bands of both target and non-target progeny snails at different ages, Fig. 8 shows the amplified fragments obtained by gel electrophoresis of susceptible $B$. alexandrina (lanes $1-3$ ), resistant $B$. alexandrina (lanes 4-6), L. truncatula (lanes 7-9), and P. acuta (lanes $10 \& 11$ ) using OPA-01. The result showed polymorphic band at $600 \mathrm{bp}$ found in senescent susceptible and in both resistant and non-target snail species .

On the other hand, Fig. 9 shows the amplified fragments obtained by gel electrophoresis of susceptible $B$. glabrata ( lanes $1-3$ ), resistant $B$. glabrata ( lanes $4-6$ ), L. truncatula ( lanes $7-9$ ) and $P$. acuta ( lanes $10 \& 11$ ) using OPA-01. The reproducible fragments showed a remarkable band at $950 \mathrm{bp}$ which is found in both adult and senescent stages of resistant B. glabrata and in all non-target species but lacked in all susceptible stages and juvenile resistant snails .

Meanwhile, the amplified fragments obtained by polacrylamide gel electrophoresis of susceptible hybrid ( lanes $1-3$ ), resistant hybrid (lanes 4-6), L. truncatula (lanes 7-9) and P. acuta (lanes 10 \& 11) using OPA-01 as represented in Fig. 10 . 
The results explained genetic polymorphism at $500 \mathrm{bp}$ found in senescent susceptible and in both resistant and non-target snail species . Genetic variability pattern of markers identified by OPA-01 from target and non-target species at the same age .

Fig. 11 shows the characteristic RAPD-PCR product profile with primer OPA-01 . Lane $M$ is DNA marker ( $50 \mathrm{bp}$ ), lanes $1 \& 2$ are juvenile of $B$. alexandrina susceptible and resistant respectively . Lanes $3 \& 4$ are juveniles of $B$. glabrata susceptible and resistant respectively . Lanes $5 \& 6$ are juveniles of hybrid strains of susceptible and resistant progeny respectively. Lane 7 is juvenile of $L$. truncatula, lane 8 is juvenile of $P$. acuta .

Fig. 12 shows RAPD-PCR products and polyacrylamide gel electrophoresis of all adult progeny snails . Lane $\mathrm{M}$ is DNA ladder ( 50 bp.). Lanes $1 \& 2$ are adult $B$. alexandrina of susceptible and resistant snails respectively . Lanes $3 \& 4$ are adult $B$. glabrata of both susceptible and resistant progeny respectively . Lanes $5 \& 6$ are hybrid susceptible and resistant progeny respectively . Lane 7 is adult of $L$. truncatula . Lane 8 is adult of $P$. acuta .

Furthermore, Figure 13 illustrates the genetic variability among target and non-target species at senescent stage . Lane $M$ is DNA marker, lanes $1 \& 2$ are $B$. alexandrina

( susceptible and resistant) respectively . Lanes $3 \& 4$ are B. glabrata ( susceptible and resistant ) respectively . Lanes $5 \& 6$ are hybrid strain ( susceptible and resistant) respectively. Lanes $7 \& 8$ are L. truncatula .

Tables 3, 4 and 5 show that related individuals belonging to the same snail species, snail type and age of either target or non-target recorded similarity coefficient nearly 1.0 , while snails belonging to the same species at different ages recorded similarity coefficient range from 0.65 $0.91,0.57-1.0$ and $0.67-0.91$ for B. alexandrina , B. glabrata and hybrid respectively. While among different ages of non-target snail species similarity coefficient recorded values range from $0.7-1.0$ ( Table 6).

\section{DISCUSSION}

The variability in susceptibility / resistance of Biomphalaria species to Schistosoma infection estimated in the current study is in agreement with many investigators, such as the results obtained by Souza et al. ( 1995 ), who demonstrated considerable variations in susceptibility in different Biomphalaria species. Such variability can even be observed in snails belonging to the same species, from different geographical areas 
( Richards, 1984). Thus, resistance or susceptibility is genetically dependent rather than acquired immunity (Richards 1976 ) which may ultimately be related to genetic background (Lemos and Andrade, 2001 ).

It has been demonstrated that miracidia penetrate in susceptible snail and differentiate into sporocysts .These display extensive proliferation, remaining viable and active, producing great number of circariae . However, in highly resistant snails, penetrating miracidia are quickly recognized and destroyed by means of amoebocytes which are capable to damage the miracidium tegument and to seriously compromise its viability ( Bayne et al., 1980 ). Such amoebocytic response according to Bayne and Yoshino ( 1989 ) interfere with particular gene combinations and each requires specific genetic activators .

The likelihood of the genetic diversity of the intermediate snail host affects schistosomiasis transmission in endemic areas, and the possibility of using refractory snails as a competitors aiming to biological control , have been discussed ( Okere and Odaibo, 2005 ). The present study applying molecular technique was coducted to determine the extent of genetic diversity among well defined Biomphalaria snails with different snail types at different developmental stages and comparing them with non-target species to $S$. mansoni infection using RAPD-PCR technique . The ability to determine resistant or susceptible markers in our laboratory-maintained Biomphalaria snails would be an important component of the current study of the potential biological control measures employing the use of refractory snails .

Moreover, the availability of isogenic snail lines has made it possible to use molecular tools to determine the degree of genetic variability between them. By comparing genetic markers in DNA genome of susceptible and non-susceptible produced or lacked that would make them non-susceptible, it might be possible to insert or delete this component in susceptible snails by treatment with specific mutagens. These genetically-altered varieties could then be released into areas endemic for schistosomes, following treatment of these areas to remove most or all of the genetically-unaltered susceptible snails. This concept will lead to genetic control of schistosomiasis .

The data presented showed that the utility of the RAPD-PCR method to differentiate snail line at different ages were selected on the bases of well characterized resistance / susceptibility of parental snail type upon exposure to $S$. mansoni . Accordingly, before emarking on the RAPD study described, a major concern was that the assay would produce a 
certain degree of polymorphic information with laboratory maintained lines of target and non- target snail species, thus providing inconsistent data for genetic differentiation. It was found that three of the eighteen used primers gave reproducible polymorphic bands but one of them , OPA-01. This method was reliable and less time consuming for producing specific RAPD profiles for all tested groups and for the identification of stable genetic markers between target and non-targets to S. mansoni infection. In a study comparable to ours, Langand et al. ( 1993 ) demonstrated that RAPD method was a useful tool for the evaluation of the degree of genetic diversity within the genus Bulinus, and other medically important gastropods to detect genetic differentiation between B. glubous and B. umblicates. Moreover Stothard and Rollinson ( 1996 ) investigated genetic differentiation among 9 bulinid snail species.

One of the major finding of the present study is that RAPD-PCR technique needs very little DNA and that it could be applied to molluscan juvenile . Besides, it is techniqally less demanding than other molecular techniques. These findings are in accordance with Vidigal et al. (1994), who reported that RAPD-PCR permits identification of very young molluscas at age when morphological and allozymic techniques cannot be used. The RAPD technique provides markers in all coding and non-coding regions of DNA genome. This makes it ideal for genetic mapping as suggested by Williams ( 1994 ):

The present study showed specific identified markers in susceptible B. alexandrina at $700 \mathrm{bp}$ in juvenile and adult stages, $620 \mathrm{bp}$ in juvenile stage only, $250 \mathrm{bp}$ in both adult and senescent stages and $200 \& 460 \mathrm{bp}$ at senescent stage only. The results also demonstrated that the average of shared bands ( similarity coeffecient ) from the same age was one and between all possible pairs at different ages ranges from 0.72 to 1.00 . Resistant $B$. alexandrina also showed genetic markers at $700 \mathrm{bp}$ in juvenile, $200 \mathrm{bp}$ in senescent, and at $180 \mathrm{bp}$ which were marked in both adult and senescent stages . Moreover, the similarity coefficient was 1.00 between snails of the same age and between different ages range between 0.79 to 1.00 .

In addition, genetic markers revealed in susceptible $B$. glabrata at $300 \mathrm{bp}$ in senescent stage only and $340 \mathrm{bp}$ in both adult and senescent stages and the appearance of $340 \mathrm{bp}$ in juvenile resistant snail type . Moreover , $150 \mathrm{bp}$ reproducible band appeared in juvenile and adult and $430 \mathrm{bp}$ in adult and senescent stages and were lacked in juvenile stage . 
Similarity coeffecient between different ages and two different types of B. glabrata ranged from 0.67 to 1.00 were also observed .

The present study demonstrated that primers OPA- 01 , OPA- 02 and OPA-18 successfully differentiated $B$. alexandrina from $B$. glabrata and provided evidence of hybrid originated under laboratory conditions . These results confirmed that hybridization may occur between $B$. alexandrina and B. glabrata in the field.

The current study also suggested genetic regulation in snail developmental stages and agreed with the suggestion of Richards and Meritt ( 1972 ), that susceptibility of juvenile snails of specific stock is controlled by a complex of genetic factors " at least four genes " and susceptible snails carry unexpressed genes for resistance and vice versa . Furthermore, the data obtained was confirmed by Richards ( 1984 ) who observed four patterns of susceptibility in B. glabrata : ( 1 ) nonsusceptible at any age ( 2 ) juvenile susceptible / adult non-susceptible ; ( 3 ) susceptible at any age (4) juvenile susceptible / adult variable.

In a comparable study to the present one, Larson et al. ( 1996 ) used RAPD-PCR to differentiate genetically different defined lines of $B$. glabrata snails, into resistant (BS-90,10-R2 and LAC lines) and susceptible ( M-line ) ones .

The interest of the present study, however, was extended to identify only stable in variant genetic markers in our laboratory stocks and comparing them with non-target species for $S$. mansoni infection to confirm resistance / susceptibility relationship. The results showed polymorphic band in B. alexandrina and non-target snail species at 600 $\mathrm{bp}$, which was produced in susceptible senescent stage only in addition to all resistant and all non-target stages. Moreover, B. glabrata in comparable with non-target snails in polyacrylamide gel electrophoresis showed a remarkable band at $950 \mathrm{bp}$ in adult and senescent stages of resistant snail type and in all non-target stages . Hybrid strain also explained genetic polymorphism between target hybrid and non-target ones at $500 \mathrm{bp}$ found in senescent susceptible, all resistant and non-target specics .

Several studies comparable to the present on had concerned with resistance / susceptibility relationship and searched for resistant gene . As performed by Vidigal et al. ( 1994 ) to determine the genetic variation in $B$. glabrata from seven Brazilian isolates to report that snails from the same isolates were relatively homogenous, with the majority of bands being common to all individual studies . In contrast, snails from different 
isolates were quite distinct . Furthermore, Shoukry et al. ( 1997 ) reported different levels of susceptibility between $B$. alexandrina from different localities with heritable refractory character. Moreover, Kristensen et al. ( 1999) used RAPD-PCR to differentiate species and populations of Biomphalaria from Egypt and differentiated Egyptian Biomphalaria from South American snail species . In addition, RAPDPCR technology was used to study genetic variation among schistosome hosts of species $B$. pfeifferi . The results showed only $6 \%$ of DNA fragments were common to all snails which come from 15 sites along 6 $\mathrm{km}$ stretch of Zimbabwean river. On the other hand, genetic variations among $B$. pfeifferi was described by Webster et al. ( 2001 ) who reported high genetic variability in population from different isolates using RAPDPCR technology . Campos et al. ( 2002 ) also used morphology and PCRRFLP for specific identification of twenty snails in each population from eight distant Brazilian localities. Bands generated after gel electrophoresis of SSR-PCR products of $B$. glabrata snails were used to study intra-and interpopulation genetic variability .

Our interest is also in agreement with Rollinson et al. ( 1998 ) who initiated a preliminary search for snail genomic regions and characterized a variety of sequence target sites associated with resistance. Furthermore, Abdel - Hamid et al. ( 1999 ) detected the genetic variability between susceptible and resistant snails of $B$. tenagophila using RAPD technology. Similar results were obtained by Knight et al. (1999) who reported that $1.2 \mathrm{~kb}$ marker produced by primer OPM-4 and $1 \mathrm{~kb}:$ marker produced by primer OPZ-11, segregating in the same dominant fashion with resistant phenotype .

In a previous study, RAPD-PCR was also used to quantify genetic diversity within and between 5 populations of $S$. mansoni with definitive host and the 5 corresponding populations of the snail intermediate host $B$. glabrata ( Sire et al., 2001 ) . Comparable to our study, Spada et al. ( 2002 ) using the same technique, demonstrated the genetic markers between $B$. glabrata snail into both susceptible and resistant. The results showed genetic polymorphism with 5 primers from 10 used primers . In addition, Da Silva et al.( 2004 ) detected the genetic resistant $B$. tenagophila to $S$. mansoni infection. The results showed different characteristic bands for susceptible strain and single characteristic bands for resistant one using different four primers. Moreover, Abdel-Hamid et al. (2005) detected characteristic band at 430 bp for Egyptian $B$. alexandrina resistant snails . 
Our interest however, was to identify only stable invariant genetic variations among all the laboratory tested groups either target or nontarget at the same age. The results showed that there is some stable bands to differentiate susceptible from resistant snail types. In adult stage there is at $240 \mathrm{bp}$ a stable polymorphic marker in all susceptible snails but is lacked in resistant and non-target species . Moreover , $400 \mathrm{bp}$ and $300 \mathrm{bp}$ were distinguished in senescent stage of all tested groups . Unstability of resistant gene in juvenile and senescent stage confirmed the age / susceptibility relationship and may resolve the problem of high frequency in juvenile susceptibility and converted them into less susceptible or completely resistant especially in old snails as reported by Richards and Meritt ( 1972 ). Similar findings that supported our results was reported by Fernandez ( 1997 ) who observed a decline in susceptibility of B.glabrata with increasing age . Fernandez and Pieri ( 2001 ) also observed a significant infection rate associated with molluscan age , being proportionally higher in sexually immature than in mature molluscs.

The present results demonstrated experimentally that distribution patterns of schistosome larvae among the snail-host population may differ depending upon host- parasite combination considered, a parameter which may have significant consequences on the transmission dynamics of the parasite and on the distribution of genetic diversity of schistosomes among the definitive host population ( Barral et al., 1993 ) . Recent molecular techniques such as analysis of repetitive polymorphic DNA element ( Minchella et al., 1995 ) or random amplified polymorphic DNA markers ( Da Silva et al. , 2004 and Abdel-Hamid et al. 2005) are now useful tools for investigating the distribution patterns of trematode larvae among naturally infected snail host .

From the previous discussion it can be concluded that host-parasite compatibility is genetically dependent and genes for resistance were revealed in resistant snails of target species and was confirmed in nontarget ones .

Therefore, the obtained results in the present work represent a starting point to determine what gene or gene products are specifically responsible for susceptibility / resistance of target snails to infection and demonstrates that RAPD-PCR is an appropriate and efficient methodological technique for distinguishing between schistosomiasis vectors 


\section{REFERENCES}

Abdel - Hamid , A. Z. ( 1996 ). Attraction of Biomphalaria alexandrina snails "intermediate hosts for Schistosoma mansoni" to different carbohydrates . Egyp. J. Bilh., 18: 39-54 .

Abdel - Hamid , A. Z.; Molfetta , J. B. ; Fernandez , V. and Rodrigues , V.(1999). Genetic variation between susceptible and nonsusceptible snails to Schistosoma infection using random amplified polymorphic DNA analysis ( RAPDs ) . Rev. Inst. Med. Trop. Sp. , $41: 291-295$.

Abdel - Hamid , A. Z.; Rawi , S. and Arafa , A. S. ( 2006 ). Identification of the genetic marker associated with the resistance to Schistosoma mansoni infection using RAPD-PCR analysis, Mem. Inst. Oswaldo Cruz., $101: 35-41$.

Barral , V.; This , P.; Imbert - Establet, D.; Combes , C. and Delseny , M. ( 1993 ). Genetic variability and evolution of the Schistosoma genome analysed by using random amplified polymorphic DNA markers . Mol. Biochem. Parasitol., 59: 211 - 222 .

Bayne , C. J.; Buckely , P. M. and Dewan , P. ( 1980 ). Macrophage like hemocytes of resistant Biomphalaria glabrata are cytotoxic for sporocysts of Schistosoma mansoni in vitro. J. Parasitology., 66 : $413-419$.

Bayne , C. J. and Yoshino , T. P. ( 1989 ). Determinants of compatibility in mollusc . Trematode Parasitism. Am. Zool., 29 : $399-407$.

Campbell , R. C. ( 1989 ). Statistics for Biologists . $3^{\text {rd }}$ ed., ( R. C. Campbell , ed. ). Cambridge University Press, Cambridge, New York ,Melbourne, Sydney, 1-25pp.

Campos , Y. R.; Carvalho , O. S.; Goveia , C. O. and Romanha , A. J. ( 2002). Genetic variability of the main intermediate host of the Schistosoma mansoni in Brazil , Biomphalaria glabrata (Gastropoda : Planorbidae) assessed by SSR-PCR . Acta Trop., $83: 19-27$. 
Da Silva , D.; Spada R. G.; Sobral-Hampaguchi , S. S.; Abdel-Hamid , A. Z.; Zuim , Z.; Magalhaes , E. M; Magalhaes , L. A. and RibeiroPaes, J. T. ( 2004 ). Biomphalaria tenagophila : genetic variability within intermediate hosts susceptible and resistant to Schistosoma infection . Parasitology, $11: 43-49$.

Fenwick , A.; Savioli , L.; Engels , D.; Bergquist , N. R.; Todd , M. H. (2003). Drug for the control of parasitic disease : current status and development in Schistosomiasis . Trends Parasitol., 19:509-515.

Fernandez, M. A. ( 1997 ). Schistosoma mansoni infections in the first three months of life of sympatric intermediate hosts from Brazil . Mem. Inst. Oswaldo Cruz. , $92: 27-29$.

Fernandez , M. A. and Pieri , O. S. ( 2001 ). Infection by Schistosoma mansoni sambon 1907 in the first four months of life of Biomphalaria straminea (Dunker, 1948 ) in Brazil . Mem. Inst. Oswaldo Cruz., $96: 185$ - 192 .

Helling, R. B.; Goodman , H. M. and Boyer , H. W. ( 1974 ). Analysis of R. Eco RI fragments of DNA from lambdoid bacteriophages and other viruses by agarose gel electrophoresis. J. Virol., 14:1235- 1238 .

Ismail , M.; Botros , S.; Metwally , A.; William , S.; Farghally , A.; Tao , L.; Day , T. A.; Bennell , J. L. ( 1999 ).Resistance to praziquantel : direct Evidence from Schistosoma mansoni isolated from Egyptian villagers . Am. Soc. Trop. Med. Hyg., 6: 932 - 935 .

Ismail , M.; Metwally , A.; Farghaly , A. M.; Bennett , J. and Tao , L. E. ( 1998 ). Praziquantel resistance to Schistosoma mansoni in Egypt . The SRP Int. Cong. Schisto. March 15 - 19, Cairo, Egypt, Abst. No. 212 .

Jobin , W. R.; Laracuente , A. and Negron , H. ( 1984 ). Inexpensive Boletin Biological control of schistosome transmission in Montebello , Puerto Rico. De La Association Medica De Puerto Rica $76: 157-160$. 
Knight , M.; Miller , A. N.; Patterson , C. N.; Rowe , C. G.; Michaels , G.; Carr , D.; Richards , C. S. and Lewis , F. A. ( 1999 ). The identification of markers segregation with resistance to Schistosoma mansoni infection in the snail Biomphalaria glabrata. Proc. N. Acad. Sci. USA, $96: 1510-1515$.

Kristensen , T. K.; Yousif , F. and Raahaug , P. ( 1999 ). Molecular characterization of Biomphalaria sp. In Egypt . J. Moll. Stud., 65 : $133-136$.

Langand , J.; Barral, V.; Delay , B. and Jourdane , J. ( 1993 ). Detection of genetic diversity within snail intermediate hosts of the genus Bulinus by using random amplified polymorphic DNA markers ( RAPDs ) . Acta Trop., $55: 205-215$.

Langand, L. and Morand, S. ( 1998 ). Heritable non-- susceptibility in an allopatric host - parasite system : Biomphalaria glabrata ( Mollusca ) Eschinostoma caproni ( platyhelminth digenea ) . J. Parasitol., 84 : $739-742$.

Larson , S. E.; Anderson , P. L.; Miller , A. N.; Cousin , C. A.; Richards , C. S.; Lewis , F. A. and Knight, M. ( 1996 ). Use of RAPD - PCR to differentiate genetically defined lines of an intermediate host of Schistosoma mansoni , Biomphalaria glabrata . J. Parasitol., 82 : $237-244$.

Lemos , Q. T. and Andrade , Z. A. ( $2001^{\circ}$ ). Sequential histological changes in Biomphalaria glabrata during the course of Shistosoma mansoni infection. Mem. Inst. Oswaldo Cruz., 96: $719-721$.

Lotfy, W. M.; Dejong, R. J.; Abdel-Kader, A. and Loker, E. S. ( 2005 ). A molecular survey of Biomphalaria in Egypt: Is B. Glabrata present? . Am. J. Trop. Med. Hyg., 73 : $131-139$.

Minchella , D. J.; Sollenberger , K. M. and Pereira , S. C. ( 1995 ). Distribution of schistosome genetic diversity within molluscan intermediate hosts . Parasitology, $111: 217-220$. 
Nei , M. and Li , W. H. ( 1979 ). Mathematical model for study genetic variation in terms of restriction endonucleases . Proc. Nat. Acad. Sci. USA . $74: 5267-5273$.

Okere , P. U. and Odaibo, A. B. ( 2005 ). Interaction between Biomphalaria pfeifferi, the snail intermediate host of Schistosoma mansoni, and Indoplanobis exustus, a possible competitor snail . Afric. J. Biotechnol., 4 : 676-678 .

Richards C. S. ( 1976 ). Variations in infectivity for Biomphalaria glabrata in strains of Schistosoma mansoni from the same geographic area . Bull. WHO, $54: 706-707$.

Richards, C. S. ( 1984 ) : Influence of snail age on genetic variations in susceptibility of Biomphalaria glabrata for infection with Schistosoma mansoni. Malacology, 25 : 493- 502.

Richards C. S. and Meritt , J. W. J. ( 1972 ). Genetic factors in the susceptibility of juvenile Biomphalaria glabrata of Schistosoma mansoni infection. Am. J. Trop. Med. Hyg., 21 : 425 - 435 .

Rodgers , S. O. and Bendich , A. J. ( 1988 ). In Plant Molecular Biology Manual ( S. B. Gelvin and R. A. Schilperooit, eds. ), pp 1-A6/ 11. Chapman and Hall. London .

Rollinson , D.; Stothard , J. R.; Jones , C. S.; Lockyer , A. E. ; de Souza , C. P. and Nobile, L. R. ( 1998 ). Molecular characterization of intermediate snail hosts and the search for resistance genes . Mem. Inst. Oswaldo Cruz., $93: 111-116$.

Ross , A. G. P.; Bartly , P. B.; Sleigh , A. C.; Olds , G. R.; Li , Y.; Williams , G. M. and Mc Manus , D. P. ( 2002 ). Schistosomiasis , N. Engl. J. Med., $346: 1212-1220$.

Sanguinetti , C. J.; Dias Neto , E. and Simpson , A. J. G. ( 1994 ). Rapid silver staining and recovery of PCR products separated on polyacrylamide gels . Bio. Tech., $17: 915-918$.

Shoukry , N. M.; El-Assal , F. M.; Soliman, G. N. and Mansour, N. S. ( 1997 ). Susceptibility of three successive snail generations from positive and negative laboratory bred Biomphalaria alexandrina 
from different localities in Egypt to infection with Schistosoma mansoni from Giza . J. Egypt. Soc. Parasitol., 27 : 317-329.

Simpson , A. J. G.; Dias Neto , E.; Steindel , M.; Gaballero , O. L. S. D.; Passos, L. K. J. and Pena, S. D. J. ( 1993 ). The use of RAPDs for the analysis of parasites . DNA Fingerprinting State of the Sciences, pp. $331-337$.

Sire , C.; Langand , J.; Barral, V. and Theron, A. ( 2001 ). Parasite ( Schistosoma mansoni) and host ( Biomphalaria glabrata) genetic diversity : Population structure in a fragmented landscape. Parasitology, $122: 545-554$.

Souza , C. P.; Janotti-Passos , L. K. and Freitas , J. R. ( 1995 ). " Degree of host-parasite compatibility between Schistosoma mansoni and their intermediate molluscan host in Brazil ". Mem. Inst. Oswaldo . Cruz., $90: 5-10$.

Spada , R. G.; Da Silva , D.; Abdel-Hamid , A. Z.; Sobral-Hamaguchi , S. S.; Zuim, N. R.; Zanotti-Magalhaes, E. M.; Magalhaes, L. A. and Ribeiro-Paes, J. T. ( 2002 ).Genetic markers between Biomphalaria glabrata snails susceptible and resistant to Schistosoma mansoni infection. Mem. Inst. Oswaldo Cruz., $97: 53-58$.

Stothard , J. R. and Rollinson, D. ( 1996 ). An evaluation of random amplified polymorphic DNA ( RAPD ) for identification and phylogeny of freshwater snails of the genus Bulinus (Gastropoda : Planorbidae ). J. Moll. Stud., 62:165-176.

Ukoli F. M. A. ( 1992 ). Prevention and control of parasitic diseases in tropical Africa . The Main Issues . Uni. Press Pic., Ibadan, 199pp.

Vidigal , T. H.; Neto, E. D.; Carvalho, O. S. and Simpson, A. J. G. (1994). Biomphalaria glabrata: Extensive genetic variation in Brazilian isolates revealed by random amplified polymorphic DNA analysis . Exp. Parasitol., 79 : 187- 194 .

Vidigal , T. H.; Neto , E. D.; Carvalho , O. S. and Simpson , A. J. G. (1996). A low stringency polymerase Chain Reaction Approach to the identification of Biomphalaria glabrata and Biomphalaria 
tenagophila, intermediate snail hosts of Schistosoma mansoni in Brazil . Mem. Inst. Oswaldo Cruz., 91 : 739 - 744.

Webster, J. P.; Davies, C. M.; Ndamba, J.; Noble, C. S.; Jones, C. S. and Woolhouse, M. E. ( 2001 ). Spatiotemporal genetic variability in the Schistosome intermediate host Biomphalaria pfeifferi . Ann. Trop. Med. Parasitol., $95: 515-527$.

Williams, C. F. ( 1994 ). Genetic consequences of seed dispersal in three sympatric forest herbs . II . Microspatial genetic structure within populations . Evolution, $48: 1959-1972$.

Winnepenninckx , B.; Backelijau, T. and de Wachter, R. ( 1993 ). Extraction of high molecular weight DNA from mollusca . Trends Gen., $9: 407$.

Zanotti - Magalhaes , E. M.; Magalhaes, L.A. and Carvalho , J. R. ( 1997 ). Relacao mtre pathogencidade do Schistosoma mansoni em camundongos ea susceptibilidade do molusco vector . IV .Infecciosidade dos miracidios . Rev. Saude Puplica, 29:265-270 . Cited from Abdel - Hamid et al. (2006). 
Fig. ( 1 ) : Profile of total genomic DNA of both susceptible and resistant B.alexandrina snails at different ages visualized by $2 \%$ agarose gel and ethidium bromide staining .

M: $123 \mathrm{bp}$ DNA ladder .

$1,2,3$ : DNA genome of susceptible $B$. alexandrina for juvenile , adult and senescent stage respectively.

4, 5, 6: DNA genome of resistant $B$. alexandrina for juvenile, adult and senescent stage respectively .

Plate : (1)

Fig. ( 2 ) : $5 \%$ silver stained polyacrylamide gel electrophoresis , showing RAPD profiles of susceptible $B$. alexandrina obtained by different primers . Lanes : $7,8,9$, : non-amplified genomic DNA of juvenile, adult and senescent using primer ( OPA-18).

Fig. ( 3 ) : $5 \%$ silver stained polyacrylamide gel electrophoresis, showing RAPD profiles of resistant $B$. alexandrina obtained by different primers . Lanes : $7,8,9$, : non-amplified genomic DNA of juvenile , adult and senescent using primer ( OPA-18).

Fig. ( 4 ) : $5 \%$ silver stained polyacrylamide gel electrophoresis, showing RAPD profiles of susceptible $B$. glabrata obtained by different primers . Lanes : $7,8,9$, : non-amplified genomic DNA of juvenile , adult and senescent using primer ( OPA-18).

Fig - ( 5 ) : $5 \%$ silver stained polyacrylamide gel electrophoresis, showing RAPD profiles of resistant $B$. glabrata obtained by different primers . Lanes : $7,8,9$, : non-amplified genomic DNA of juvenile , adult and senescent using primer ( OPA-18).

Fig. ( 6 ) : $5 \%$ silver stained polyacrylamide gel electrophoresis, showing RAPD profiles of susceptible hybrid obtained by different primers . Lanes : 7, 8, 9 : amplified genomic DNA of juvenile, adult and senescent using primer ( OPA-18).

Fig. ( 7 ): $5 \%$ silver stained polyacrylamide gel electrophoresis, showing RAPD profiles of resistant hybrid obtained by different primers . Lanes : $7,8,9$ : amplified genomic DNA of juvenile, adult and senescent using primer ( OPA-18).

$\mathrm{M}: 50$ bp. DNA ladder .

Lanes : 1, 2, 3 : amplified genomic DNA of juvenile, adult and senescent using primer ( OPA-01).

Lanes : $4,5,6$, : amplified genomic DNA of juvenile , adult and senescent using primer ( OPA-02). 
Plate : ( 2 )

Fig. ( 8 ) : Comparison of OPA-01 RAPD products from target (B. alexandrina) and non- target (L. truncatula and P. acuta) .

Fig. ( 9 ) : Comparison of OPA-01 RAPD products from target (B. glabrata) and non-target (L. truncatula and P. acuta) .

Fig. ( 10 ) : Comparison of OPA-01 RAPD products from target (hybrid) and non-target ( L. truncatula and P. acuta) .

$\mathrm{M}: 50$ bp DNA ladder .

Lanes : 1, 2, $3:$ Juvenile, adult and senescent of target susceptible snails respectively .

Lanes : 4, 5, 6: Juvenile, adult and senescent of target resistant snails respectively .

Lanes : 7, 8, 9 : Juvenile, adult and senescent of $L$. truncatula snails respectively .

Lanes : 10,11 : juvenile and adult of $P$. acuta snails respectively .

Fig. ( 11 ) : Genetic variations revealed in target and non-target snail species at juvenile stage obtained by primer ( OPA-01).

Fig. ( 12 ) : Genetic variations revealed in target and non-target snail species at adult stage obtained by primer ( OPA-01).

Fig. ( 13 ) : Genetic variations revealed in target and non-target snail species at senescent stage obtained by primer ( OPA-01). Lanes 7, $8 \mathrm{~L}$. truncatula .

$\mathrm{M}: 50 \mathrm{bp}$ DNA ladder .

Lanes :1, 2:B. alexandrina susceptible and resistant snails respectively.

Lanes : $3,4: B$. glabrata of susceptible and resistant snails respectively.

Lanes : $5,6:$ hybrid of susceptible and resistant snails respectively .

Lanes : $7:$ L. truncatula .

Lanes : $8:$ P. acuta. 


\section{MOLECULAR GENETIC VARIATIONS AMONG POPULATIONS 45 OF SCHISTOSOMA INFECTION}

Table (1): Spectrophotometric determination of genomic DNA extracted from head foot region of different snails at different ages of target Biomphalaria snail species.

\begin{tabular}{|c|c|c|c|c|c|c|c|}
\hline & \multirow{2}{*}{ Snail species } & \multicolumn{2}{|c|}{ Juvenile } & \multicolumn{2}{|c|}{ Adult } & \multicolumn{2}{|c|}{ Senescent } \\
\hline & & $\begin{array}{l}\text { Suscep tible } \\
\mathrm{M} \pm \mathrm{SE}\end{array}$ & $\begin{array}{c}\text { Resistant } \\
\mathrm{M} \pm \mathrm{SE}\end{array}$ & $\begin{array}{c}\text { Susceptible } \\
\mathrm{M} \pm \mathrm{SE}\end{array}$ & $\begin{array}{r}\text { Resistant } \\
\mathrm{M} \pm \mathrm{SE}\end{array}$ & $\begin{array}{c}\text { Susceptible } \\
\qquad \begin{array}{c}M \\
\text { SE }\end{array}\end{array}$ & $\begin{array}{r}\text { Resistant } \\
M \pm S E\end{array}$ \\
\hline \multirow{3}{*}{$\begin{array}{l}\text { Weight } \\
\text { of suails } \\
\text { foot (mg) }\end{array}$} & B. alexandrina & $8.01 \pm 0.10$ & $8.10 \pm 0.15$ & $50.01 \pm 1.15$ & $50.32 \pm 1.25$ & $101.00 \pm 2.30$ & $101.17 \pm 2.4$ \\
\hline & B. glabrata & $8.09 \pm 0.30$ & $8.05 \pm 0.07$ & $51.50 \pm 0.25$ & $50.8 \pm 0.70$ & $105.90 \pm 2.01$ & $103.0 \pm 0.99$ \\
\hline & Hybrid & $8.09 \pm 0.25$ & $8.03 \pm 0.05$ & $50.34 \pm 0.40$ & $50.10 \pm 0.60$ & $103.60 \pm 0.90$ & $102.0 \pm 0.79$ \\
\hline \multirow{3}{*}{$\begin{array}{l}\text { DNA } \\
\text { purity }\end{array}$} & B. alexandrina & $1.77 \pm 0.08$ & $1.75 \pm 0.05$ & $1.78 \pm 0.09$ & $1.72 \pm 0.08$ & $1.76 \pm 0.07$ & $1.71 \pm 0.08$ \\
\hline & B. glabrata & $1.72 \pm 0.09$ & $1.79 \pm 0.06$ & $1.70 \pm 0.13$ & $1.80 \pm 0.08$ & $1.70 \pm 0.10$ & $1.77 \pm 0.13$ \\
\hline & Hybrid & $1.84 \pm 0.01$ & $1.79 \pm 0.09$ & $1.82 \pm 0.08$ & $1.81 \pm 0.11$ & $1.83 \pm 0.05$ & $1.82 \pm 0.06$ \\
\hline \multirow{3}{*}{$\begin{array}{l}\text { DNA } \\
\text { conc. } \\
(\mu \mathrm{g} / \mu \mathrm{l})\end{array}$} & B. alexandrina & $11.12 \pm 0.70$ & $12.15 \pm 0.80$ & $69.50 \pm 4.50$ & $75.95 \pm 5.20$ & $140.0 \pm 7.50$ & $152.30 \pm 8.95$ \\
\hline & B. glabrata & $12.80 \pm 0.75$ & $12.32 \pm 0.59$ & $80.40 \pm 4.12$ & $27.80 \pm 3.25$ & $164.8 \pm 8.50$ & $159.70 \pm 7.9$ \\
\hline & Hybrid & $12.10 \pm 0.52$ & $11.90 \pm 0.91$ & $76.00 \pm 3.20$ & $75.00 \pm 3.50$ & $153.0 \pm 6.20$ & $149.00 \pm 5.90$ \\
\hline
\end{tabular}


Table (2): Spectrophotometric determination of genomic DNA extracted from head foot region at different ages of non-target snail species.

\begin{tabular}{|c|c|c|c|c|}
\hline & Snail species & $\begin{array}{c}\text { Juvenile } \\
\mathbf{M} \pm \mathbf{S E}\end{array}$ & $\begin{array}{c}\text { Adult } \\
\mathbf{M} \pm \mathrm{SE}\end{array}$ & $\begin{array}{c}\text { Senescent } \\
\mathbf{M} \pm \mathrm{SE}\end{array}$ \\
\hline $\begin{array}{c}\text { Weight of } \\
\text { snails } \\
\text { foot } / \mathrm{mg})\end{array}$ & L. truncatula & $8.09 \pm 0.20$ & $60.32 \pm 1.92$ & $119.23 \pm 2.01$ \\
\cline { 2 - 5 } & P. acuta & $7.99 \pm 0.03$ & $46.75 \pm 0.97$ & $90.23 \pm 2.01$ \\
\hline \multirow{2}{*}{$\begin{array}{c}\text { DNA } \\
\text { purity }\end{array}$} & L. truncatula & $1.69 \pm 0.09$ & $1.79 \pm 0.08$ & $1.80 \pm 0.06$ \\
\cline { 2 - 5 } $\begin{array}{c}\text { DN } \wedge \text { conc. } \\
(\mu \mathrm{g} / \mu \mathrm{l})\end{array}$ & L. truncatula & $12.53 \pm 0.82$ & $84.05 \pm 4.14$ & $168.48 \pm 3.96$ \\
\cline { 2 - 5 } & P. acuta & $11.02 \pm 0.76$ & $67.13 \pm 3.95$ & $135.01 \pm 4.83$ \\
\hline
\end{tabular}

Table ( 3 ): Nei's similarity coefficient among different ages of $B$. alexandrina of two different snail types using primer OPA-01.

\begin{tabular}{|c|c|c|c|c|c|c|c|}
\hline \multirow{2}{*}{ B. alexandrina } & \multicolumn{3}{|c|}{ Resistant } & \multicolumn{3}{c|}{ Susceptible } \\
\cline { 2 - 8 } & J. & Ad. & Se. & J. & Ad. & Se. \\
\hline \multirow{3}{*}{ Resistant } & J. & 1.0 & 0.85 & 0.79 & 0.67 & 0.83 & 0.91 \\
\cline { 2 - 8 } & Ad. & 0.85 & 1.0 & 0.81 & 0.67 & 0.69 & 0.85 \\
\cline { 2 - 8 } & Se. & 0.79 & 0.81 & 1.0 & 0.65 & 0.71 & 0.76 \\
\hline \multirow{3}{*}{ Susceptible } & J. & 0.67 & 0.67 & 0.65 & 1.0 & 0.72 & 0.76 \\
\cline { 2 - 8 } & Ad. & 0.83 & 0.69 & 0.71 & 0.72 & 1.0 & 0.87 \\
\cline { 2 - 8 } & Se. & 0.91 & 0.85 & 0.76 & 0.76 & 0.87 & 1.0 \\
\hline
\end{tabular}

Table (4): Nei's similarity coefficient among different ages of $B$. glabrata of two different snail types using primer OPA-01.

\begin{tabular}{|c|c|c|c|c|c|c|c|}
\hline \multirow{2}{*}{ B. glabrata } & \multicolumn{3}{|c|}{ Resistant } & \multicolumn{3}{c|}{ Susceptible } \\
\cline { 2 - 8 } & J. & 1.0 & 0.67 & 0.57 & 0.875 & 0.94 & 0.74 \\
\hline \multirow{3}{*}{ Resistant } & Ad. & 0.67 & 0.1 & 0.77 & 0.88 & 0.80 & 0.67 \\
\cline { 2 - 8 } & Se. & 0.57 & 0.76 & 1.0 & 0.82 & 0.70 & 0.82 \\
\hline \multirow{3}{*}{ Susceptible } & J. & 0.88 & 0.88 & 0.82 & 1.0 & 1.0 & 0.8 \\
\cline { 2 - 8 } & Ad. & 0.94 & 0.80 & 0.70 & 1.0 & 1.0 & 0.70 \\
\cline { 2 - 8 } & Se. & 0.74 & 0.67 & 0.82 & 0.92 & 0.70 & 1.0 \\
\hline
\end{tabular}


MOLECULAR GENETIC VARIATIONS AMONG POPULATIONS 47 OF SCHISTOSOMA INFECTION

Table (5): Nei's similarity coefficient among different ages of Hybrid species of two different snail types using primer OPA-01.

\begin{tabular}{|c|c|c|c|c|c|c|c|}
\hline \multicolumn{2}{|c|}{ Hybrid } & \multicolumn{3}{c|}{ Resistant } & \multicolumn{3}{c|}{ Susceptible } \\
\cline { 2 - 8 } & & J. & Ad. & Se. & J. & Ad. & Se. \\
\hline \multirow{3}{*}{ Resistant } & J. & 1.0 & 0.85 & 0.80 & 0.82 & 0.87 & 0.89 \\
\cline { 2 - 8 } & Ad. & 0.85 & 1.0 & 0.81 & 0.72 & 0.86 & 0.77 \\
\cline { 2 - 8 } & Se. & 0.80 & 0.81 & 1.0 & 0.67 & 0.83 & 0.84 \\
\hline & J. & 0.82 & 0.72 & 0.67 & 1.0 & 0.84 & 0.79 \\
\hline Susceptible & Ad. & 0.87 & 0.86 & 0.83 & 0.84 & 1.0 & 0.91 \\
\hline & Se. & 0.89 & 0.77 & 0.84 & 0.79 & 0.91 & 1.0 \\
\hline
\end{tabular}

Table (6): Nei's similarity coefficient among different ages of non-target species using primer OPA-01.

\begin{tabular}{|c|r|c|c|c|c|c|}
\hline \multicolumn{2}{|c|}{ Snail species } & \multicolumn{3}{c|}{ L. truncatula } & \multicolumn{2}{c|}{ P. acuta } \\
\cline { 3 - 7 } \multicolumn{2}{c|}{} & J. & Ad. & Se. & J. & Ad. \\
\hline \multirow{3}{*}{ Snail age } & J. & 1.0 & 0.94 & 0.97 & 0.1 & 0.74 \\
\cline { 2 - 7 } & Ad. & 0.94 & 0.1 & 0.95 & 0.74 & 0.1 \\
\cline { 2 - 7 } & Se. & 0.97 & 0.95 & 0.1 & - & - \\
\hline
\end{tabular}




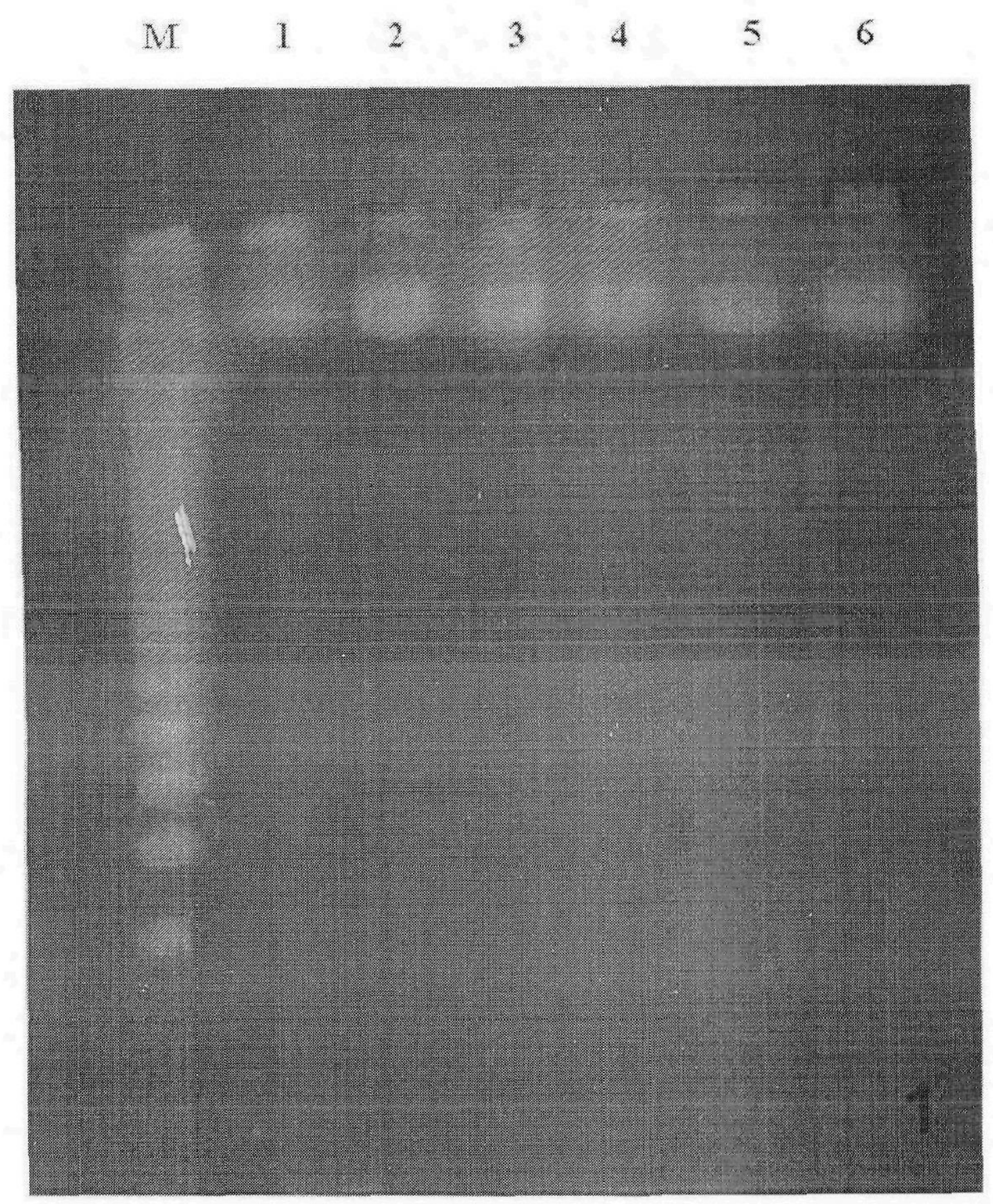



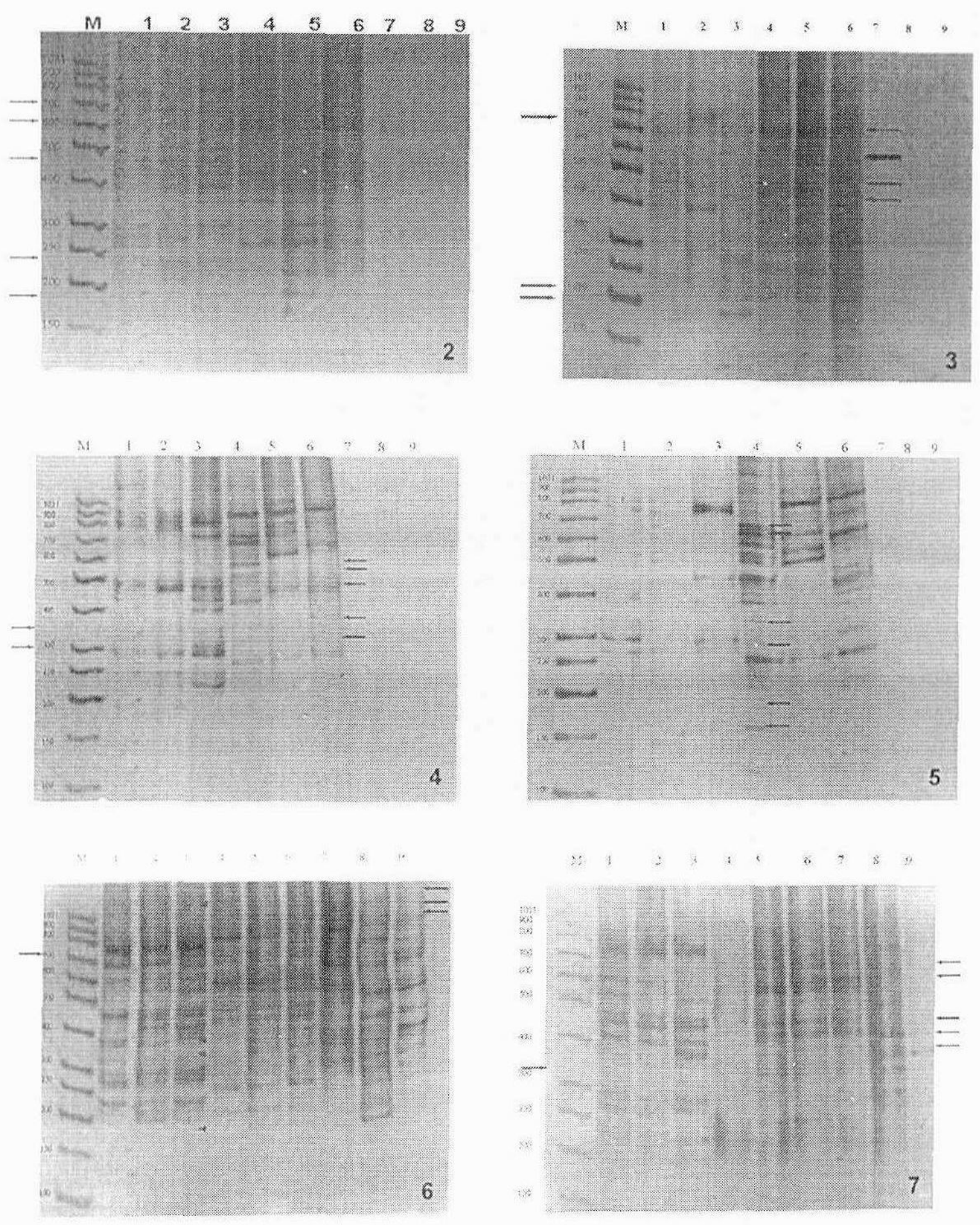

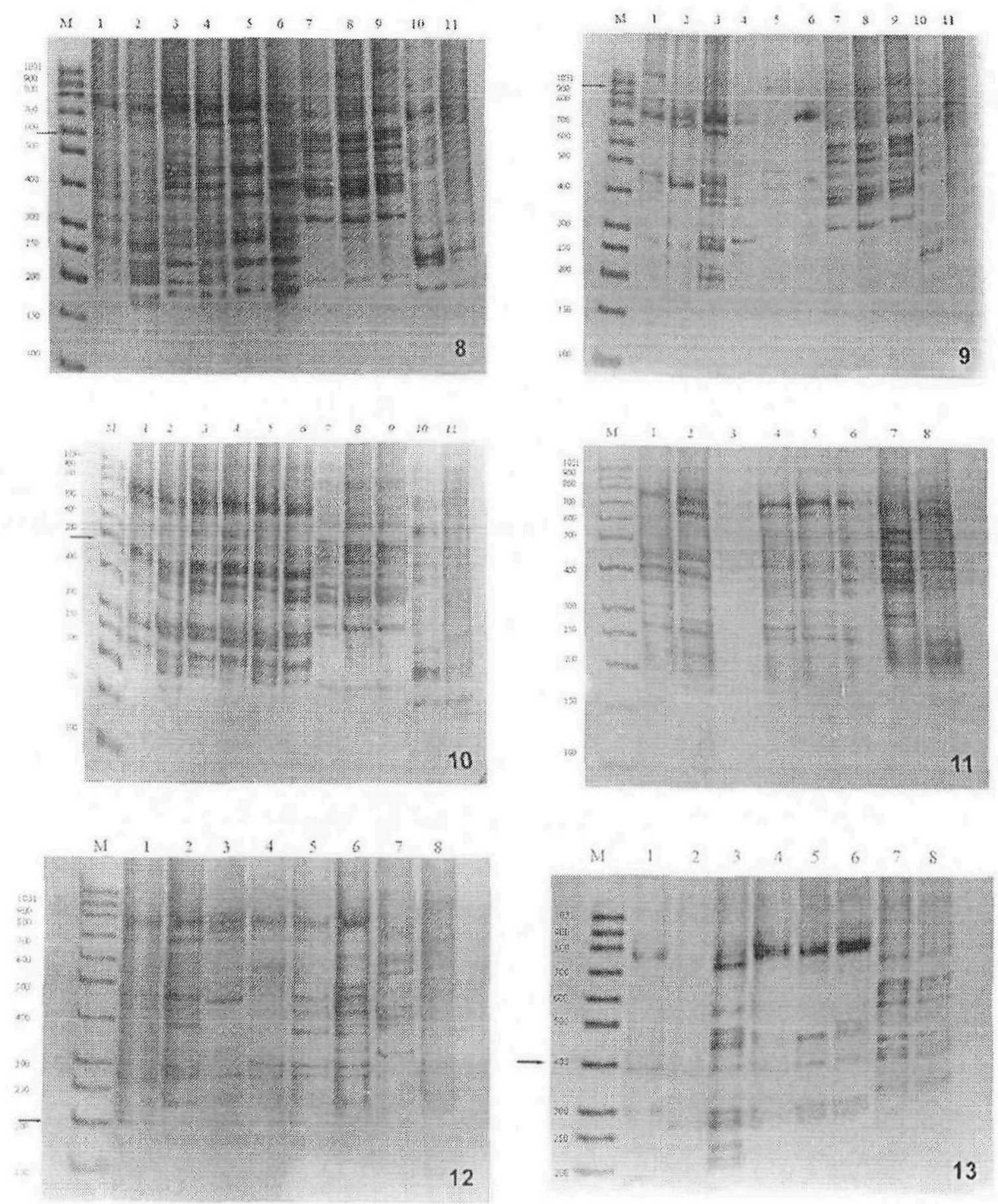